\title{
Resíduos químicos produzidos em equipamentos de análises hematológicas: conhecimento e práticas nos laboratórios
}

Primeira submissão em 25/04/11 Última submissão em 06/05/11 Aceito para publicação em 18/05/11 Publicado em 20/02/12

\section{Chemical waste produced by hematological analysis equipment: awareness and practices in laboratories}

Eliana Mara Fortunato de Lucena Reynaldo'; Paulo Roberto Janissek²; Eliane Carvalho Vasconcelos ${ }^{3}$

\begin{abstract}
unitermos
Resíduo químico

Hematologia

Conscientização

Danos ambientais

\section{resumo}

Introdução: $\mathrm{O}$ aumento de tecnologia e equipamentos automatizados em laboratórios de análises clínicas permitiu ampliar significativamente a capacidade de análises e processamento de informações. Entretanto, aumentou também na mesma proporção a utilização de reagentes químicos nas análises, gerando resíduos que, se descartados de forma incorreta, causam sérios danos ao meio ambiente. Objetivo: avaliar a informação e a conscientização dos profissionais de laboratórios de análises clínicas em relação a possíveis danos ambientais causados pelos resíduos químicos produzidos, forma de descarte adotada e interesse em receber informações relacionadas. Material e métodos: Foram realizadas entrevistas, estruturadas em questionário, para obter a quantidade de análises hematológicas realizadas na cidade de Curitiba/PR, o modo de descarte dos resíduos gerados pelos equipamentos automatizados e, também, para inferir sobre o conhecimento dos profissionais quanto à formulação das soluções, à forma recomendada de descarte e ao potencial para causar danos ao meio ambiente. Resultados e conclusão: A maioria (80\%) dos profissionais de laboratórios de análises clínicas acredita ser responsável pelo resíduo produzido, no entanto não possui conhecimento sobre a questão. Esse desconhecimento propicia práticas inadequadas em $47 \%$ dos laboratórios pesquisados, que descartam o resíduo diretamente na rede coletora de esgotos. Para evitar a contaminação biológica, 20\% dos laboratórios tratam os resíduos com hipoclorito antes de descartá-los na rede coletora de esgoto, e apenas $12 \%$ deles possuem tratamento para efluentes, porém esse tipo de procedimento realizado é desconhecido.
\end{abstract}

\section{abstract}

Introduction: The widespread use of technology and automated equipment in clinical laboratories has allowed to expand analysis capacity and information processing significantly. However, it has also augmented the use of chemical reagents in analyses, generating waste that, if improperly disposed, may cause serious environmental damage. Objectives: To evaluate the knowledge and awareness of clinical laboratory professionals as to the potential environmental damage caused by chemical waste, adopted forms of disposal, and interest in receiving related information. Methods: Interviews were conducted in a structured questionnaire in order to assess the total number of blood tests performed in the city of Curitiba and the forms of waste disposal generated by automated equipment. They were also developed to infer professionals' knowledge regarding solution development, recommended ways of disposal, and potential environmental hazard. Results and Conclusion: The vast majority (80\%) of professionals in clinical laboratories believes to be responsible for the produced waste, but has no knowledge on the issue. This unawareness generates inadequate practices in $47 \%$ of surveyed laboratories, which discard waste directly into the sewer system. In order to avoid biological contamination, $20 \%$ of the laboratories treat their waste with sodium hypochlorite before disposal into the sewer system, and only $12 \%$ have sewage treatment, though its type is unknown. key words

Chemical residue

Hematology

Awareness

Environmental damage

1. Mestra em Cestão Ambiental; gerente e responsável técnica do Laboratório do Hospital da Cruz Vermelha/PR.

2. Doutor em Química; professor do Mestrado em Gestão Ambiental da Universidade Positivo.

3. Doutora em Química; professora do Mestrado em Cestão Ambiental da Universidade Positivo. 


\section{Introdução}

O aumento populacional e a intensidade da industrialização são os principais fatores que deram origem à grande produção de resíduos, entre os quais se destaca o lixo urbano ${ }^{(9)}$. A partir da segunda metade do século XX, com os novos padrões de consumo da sociedade industrial, a produção de resíduos foi crescendo continuamente em ritmo superior à capacidade de absorção pela natureza. Além disso, cresce a cada dia a diversidade de produtos com componentes e materiais de difícil degradação e maior toxicidade ${ }^{(1)}$

A saúde da população é afetada devido às condições precárias do gerenciamento dos resíduos no Brasil, uma vez que isso causa a contaminação da água, do solo e da atmosfera, a proliferação de vetores e afeta a saúde dos trabalhadores que têm contato com esses resíduos. Esses problemas são agravados quando se constata o descaso com o gerenciamento dos resíduos de saúde ${ }^{(5)}$.

"A medicina laboratorial cresce cada vez mais no que se refere à importância científica e na sua utilização para a tomada de decisões médicas, sendo que o peso das informações geradas pelo setor de diagnóstico chega a ser de até $70 \%$ nos processos cognitivos dos clínicos"(14).

Desde a descoberta da célula até as modernas técnicas de DNA recombinante, muito aconteceu fazendo com que o laboratório clínico se tornasse centro de apoio e diagnóstico importante. Modernas técnicas e tecnologias foram e continuam sendo implantadas. A evolução da ciência médica trouxe consigo a necessidade de métodos diagnósticos cada vez mais sensíveis e precisos, o que gera quase sempre maior custo(11).

A automação e a informação tornam o laboratório mais produtivo, eficiente e controlado(11).

A confiabilidade dos resultados analíticos é de extrema importância, visto que eles fundamentam decisões médicas e refletem diretamente na segurança do paciente. Existem diversas ferramentas e metodologias para monitorar e reduzir os erros e incertezas dos resultados laboratoriais(4).

Dentro das análises clínicas, o hemograma, que faz parte das análises hematológicas, é um exame relativamente simples e um dos mais solicitados que auxilia na evolução diagnóstica ${ }^{(2,12)}$. No laboratório do Hospital Universitário da Universidade Federal de Santa Catarina, entre os exames atendidos, as solicitações de hemograma correspondem a aproximadamente $40 \%$ das requisições médicas ${ }^{(8)}$. A diversidade de informações que o hemograma pode fornecer, embora, em geral, bastante inespecíficas, torna esse exame subsidiário um dos mais solicitados nas práticas clínica e cirúrgica ${ }^{(7) .}$

Para a realização do hemograma são utilizadas substâncias como cianeto de potássio, dimetilureia e ácido fórmico que, mesmo em pequenas quantidades, podem trazer prejuízos à saúde do homem, dos animais e também ao meio ambiente ${ }^{(3,6,10,13)}$.

A falta de trabalhos e pesquisas sobre o assunto e a ausência de procedimentos ou orientações específicas para fornecedores e usuários dos reagentes agrava a situação e justifica o desenvolvimento de trabalhos que possam contribuir para minimizar esses problemas.

O descarte dos equipamentos de hematologia pode apresentar toxicidade química, pois os reagentes possuem substâncias consideradas tóxicas e contaminantes ao homem e ao meio ambiente, mesmo em concentrações muito baixas. Entre os compostos utilizados estão:

- cianeto de potássio - é tóxico para várias espécies aquáticas, terrestres e aéreas por bloquear o transporte de oxigênio no metabolismo ${ }^{(6)}$;

- ácido fórmico - é um metabólito produzido pelo metanol e atua sobre a retina, o nervo óptico e os gânglios basais em humanos ${ }^{(13)}$. Outro estudo reporta que o ácido fórmico pode causar acidose metabólica e cegueira ${ }^{(3)}$;

- dimetilureia: dano em DNA obtido de leucócitos humanos, observado por meio do ensaio do cometa, e atribuído à liberação do formaldeído por tecidos tratados com dimetilureia ${ }^{(10)}$.

\section{Material e métodos}

\section{Elaboração do questionário}

Um questionário foi formulado para verificar a quantidade de análises hematológicas realizadas na cidade de Curitiba, a maneira de descarte utilizada para os equipamentos automatizados e, também, para inferir sobre o conhecimento dos profissionais quanto à formulação dos reagentes, do descarte e do seu potencial causador de danos ao meio ambiente.

Antes de efetuar a pesquisa, a adequação e a melhor forma de aplicação do questionário foi avaliada com a colaboração de três laboratórios da região metropolitana de Curitiba e as respostas desses laboratórios não foram 
consideradas na avaliação dos dados. O primeiro questionário foi enviado via e-mail para um laboratório da região de Colombo; o segundo foi enviado via correio para um laboratório de São José dos Pinhais e, com outro laboratório de São José dos Pinhais, a pesquisa foi realizada via telefone. Os profissionais dos dois primeiros reportaram dificuldades para entender e responder adequadamente às perguntas, além de demorar muito tempo para devolver o questionário preenchido. A abordagem via telefone se mostrou mais adequada, já que a receptividade foi maior e as respostas foram imediatas, além de apontar a necessidade de reformular algumas questões no sentido de melhorar a clareza.

Após as adequações, as entrevistas para obter as respostas do questionário (anexo) foram realizadas por telefone com 34 laboratórios inscritos no Conselho Regional de Farmácia do Estado do Paraná, de onde a listagem foi obtida. Dos 42 laboratórios ativos inscritos no referido Conselho, 34 responderam às perguntas, em quatro os responsáveis não foram encontrados e três não quiseram responder à pesquisa.

\section{Volume de descarte}

Por meio dos questionários, fez-se uma estimativa de análises e constatou-se que em Curitiba são realizados em média 6.300 exames diários. O volume gerado pelo descarte foi calculado mediante simulação do procedimento operacional padrão do equipamento de análises modelo Maxym da Beckman Coulter. O volume de solução gerado pela realização de um procedimento de inicialização e de um de lavagem (procedimentos realizados automaticamente no início e final da jornada de trabalho) e também de 10 análises hematológicas foi medido com o auxílio de proveta.

O volume mensal de solução descartada na rede de esgoto da cidade de Curitiba foi calculado relacionando a quantidade de análises hematológicas diárias com o volume correspondente de descarte. Embora os laboratórios utilizem diferentes equipamentos, estes operam em condições semelhantes e o volume total de resíduos foi calculado a partir dos dados determinados para o modelo Maxym.

\section{Resultados}

Com o crescente número de exames e a automatização dos equipamentos houve aumento na geração de resíduos que são potencialmente tóxicos tanto ao homem quanto ao meio ambiente. Apesar do volume e da existência de uma legislação para esse resíduo, ela não é efetivamente aplicada e o problema é de grande relevância. Isso porque os resíduos líquidos são, via de regra, eliminados diretamente na rede coletora de esgotos.

Outro problema é a escassez de trabalhos científicos relacionando os possíveis impactos ambientais com o aumento da automação utilizada em laboratórios de análises clínicas, o uso de grande quantidade de produtos químicos e o descarte dessa mistura.

Este trabalho tem como objetivo avaliar a informação e a conscientização dos profissionais que trabalham em ambiente laboratorial em relação aos resíduos produzidos, seus possíveis danos causados ao meio ambiente e o interesse em informações relacionadas.

O volume gerado pelo descarte de 10 análises hematológicas, incluindo 1 procedimento de inicialização e 1 de limpeza, foi medido com o auxílio de proveta e o resultado obtido segue na Tabela 1.

\section{Volume de descarte produzido pelo}

Tabela 1 equipamento Maxym da Beckman Coulter

Volume ( $\mathrm{ml}$ ) de solução de descarte

Número gerado conforme o procedimento

de análise

Descarte Inicialização Limpeza Total

\begin{tabular}{|c|c|c|c|c|}
\hline 10 & 630 & 160 & 400 & 1.190 \\
\hline 100 & 6.300 & 160 & 400 & 6.860 \\
\hline
\end{tabular}

Os detalhes para obter o volume total de aproximadamente $13 \mathrm{~m}^{3}$ de descarte eliminado mensalmente na rede de esgoto da cidade de Curitiba seguem na Tabela 2.

Cálculo do volume de resíduos descartado dos equipamentos de análises Tabela 2 na rede de esgoto da cidade de Curitiba

\begin{tabular}{|c|c|c|}
\hline $\begin{array}{c}\text { Número de } \\
\text { análises/dia }\end{array}$ & $\begin{array}{c}\text { Volume (L)/ } \\
\text { dia }\end{array}$ & $\begin{array}{c}\text { Volume (L)/ } \\
\text { mês }\end{array}$ \\
\hline 100 & 6,86 & 205,80 \\
\hline 6.300 & 432,18 & $12.965,40$ \\
\hline
\end{tabular}

As respostas obtidas desses laboratórios foram expressas em porcentagem simples, considerando-se um universo de 34 laboratórios, e os resultados obtidos são apresentados nas Figuras 1, 2 e 3.

A distribuição do tipo de equipamento utilizado para realizar as análises hematológicas está representada na Figura 1. 


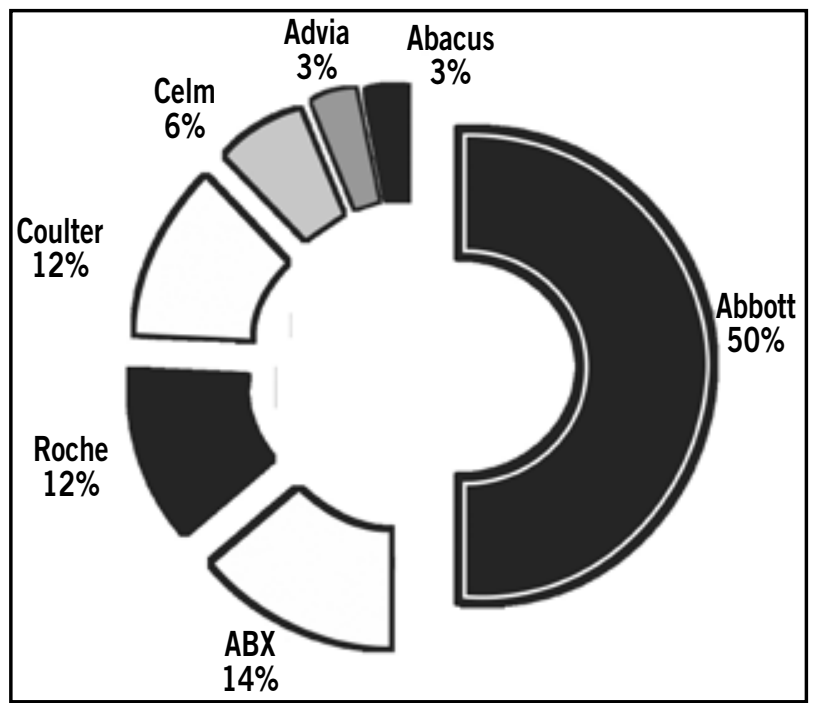

Figura 1 - Distribuição dos tipos de equipamentos de hematologia utilizados pelos laboratórios em Curitiba

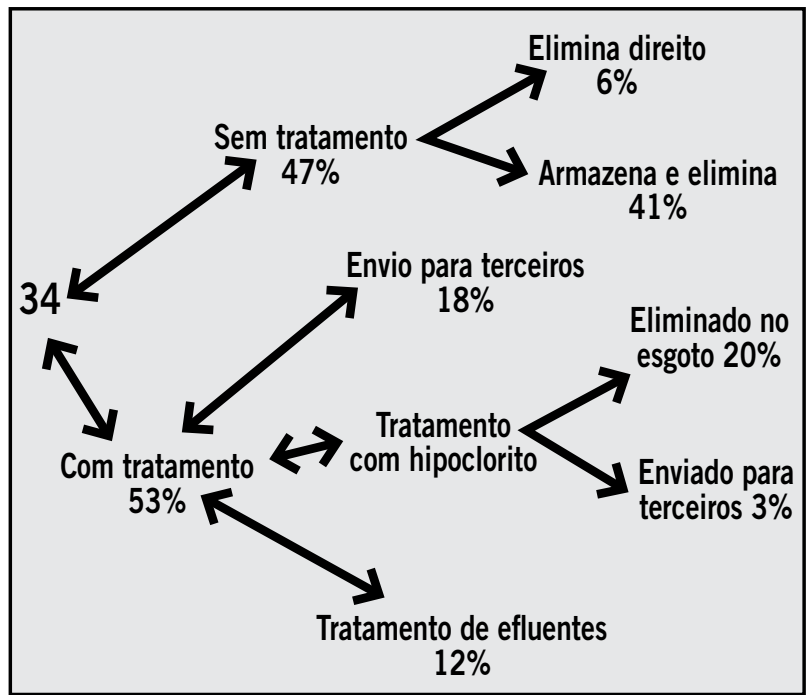

Figura 2 - Representação das formas de eliminação do descarte de equipamentos de hematologia praticadas nos laboratórios em Curitiba

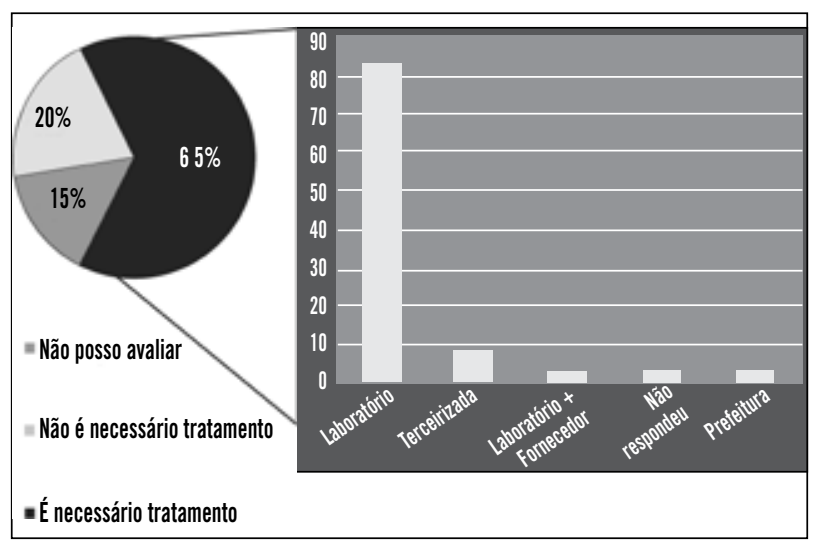

Figura 3 - Resultado da pesquisa realizada com os 34 laboratórios sobre o tratamento do descarte do equipamento de hematologia e a opinião sobre a responsabilidade de tratar o descarte dos equipamentos
Dos 7 diferentes equipamentos encontrados somente 1 deles, o Celm, possui metodologia diferente dos demais, mas os reagentes utilizados têm formulação semelhante aos usados nos outros equipamentos.

A Figura 2 demonstra a maneira de descarte realizada pelos laboratórios na cidade de Curitiba. Apenas 12\% dos laboratórios possuem tratamento de efluentes, e este é normalmente realizado pelo próprio hospital, entretanto os representantes não souberam informar a maneira de tratamento realizada. Dos 34 laboratórios, a maioria, 47\%, descarta diretamente na rede coletora; os que tratam previamente, $20 \%$, somente se preocupam com a contaminação biológica, tratando com hipoclorito de sódio. Após esse tratamento, o procedimento ainda é o descarte na rede de esgotos; $18 \%$ enviam todo o descarte para a empresa terceirizada que deve fazer o tratamento químico e a disposição final; $6 \%$ eliminam diretamente no esgoto com tubulação vinda do equipamento e $41 \%$ eliminam na rede coletora, acondicionando primeiramente em embalagem de reagente vazia.

A maioria dos entrevistados (80\%) acredita que 0 descarte é de sua responsabilidade. Acerca do tratamento, $65 \%$ o consideram imprescindível, $15 \%$ admitem não poder avaliá-lo e apenas $20 \%$ ainda não o consideram necessário por julgarem que não ocorram danos, como está demonstrado na Figura 3.

Considerando a quantidade de laboratórios que julgam necessário o tratamento (65\%) e a quantidade que realmente trata o descarte (12\%) fica clara a necessidade urgente de ações para reverter esse quadro. Entre as ações sugeridas, estão a maior divulgação por meio de cursos, treinamentos e informações sobre o conteúdo dos descartes e seus possíveis danos ambientais.

A maioria dos laboratórios considera importante tratar o resíduo por acreditar que ele possa causar algum dano, mas não sabe quais produtos químicos mais tóxicos presentes na composição dos reagentes devam receber atenção especial. A minoria, menos de 10\%, não mostrou interesse em receber mais informações sobre o assunto.

Entre as sugestões de melhorias recebidas, um entrevistado apontou que o hospital onde o laboratório está localizado deveria ter um tratamento de efluentes, e outro sugere que a prefeitura construa cisternas para a coleta do resíduo, passando a cobrar por esse serviço.

Apesar da diversidade de opiniões, a responsabilidade é dos fabricantes, fornecedores e profissionais que utilizam os equipamentos, uma vez que todos estão envolvidos no 
processo. A desinfecção com hipoclorito, tratamento realizado e/ou sugerido por alguns laboratórios, não é eficaz em relação ao descarte em questão, pois esse tratamento não retira os resíduos químicos existentes na solução.

\section{Conclusão}

O levantamento realizado neste trabalho por meio de questionários e entrevista constatou a realização média diária de 6.300 exames de hematologia na cidade de Curitiba. Estima-se que sejam eliminados mensalmente aproximadamente $13 \mathrm{~m}^{3}$ de resíduos líquidos provenientes dos equipamentos de hematologia. Esse descarte contém vários reagentes químicos com grande potencial de danos ambientais. A análise dos dados indicou que a maioria dos profissionais que trabalham em laboratórios de análises clínicas (mais de 80\%) acredita ser responsável pelo resíduo produzido, no entanto não possui conhecimento algum do seu conteúdo ou práticas adequadas de descarte. Esse desconhecimento propicia práticas inadequadas, pois dos 34 laboratórios pesquisados, $47 \%$ descartam o resíduo diretamente na rede coletora de esgotos, $20 \%$ se preocupam com a contaminação biológica e apenas $12 \%$ possuem tratamento para efluentes, porém não sabem informar a maneira como é feito esse procedimento.

\section{Anexo}

Questionário aplicado aos laboratórios de análises clínicas situados na cidade de Curitiba. As informações para contato foram fornecidas pelo Conselho Regional de Farmácia do Estado do Paraná. Os dados obtidos serão utilizados na dissertação de Mestrado Profissional em Gestão Ambiental da Universidade Positivo realizada pela mestranda farmacêutica bioquímica Eliana Mara Fortunato Reynaldo, tendo como tema "Avaliação de resíduos gerados nas análises hematológicas".

\section{Laboratório:}

\section{Responsável:}

1. Qual equipamento de hematologia possui?

2. Qual a quantidade de hemogramas realizados diariamente e o total mensal?

3. Como é o descarte das soluções?

4. É recolhido em bombonas ou em recipiente de reagente vazia?
( ) $\operatorname{sim}($ ) não

5. Se sim, o que é feito quando completa?

6. É conectada diretamente a rede de esgotos? ( ) $\operatorname{sim}($ ) não

7. Possui algum tratamento para o descarte dos equipamentos?

8. É necessário tratar a solução de descarte? ( ) sim ( ) não ( ) não posso avaliar/não tenho informação

9. Sabe de quem é a responsabilidade do descarte de equipamentos automatizados?

( ) $\operatorname{sim}$ ( ) não

10. De quem você acha que é a responsabilidade?

11. Sabe o que contém o resíduo dos equipamentos?

12. Considera que o descarte do resíduo ocasione algum dano?

13. Tem alguma sugestão de melhoria?

14. Tem interesse em receber mais informações sobre o assunto?

( ) $\operatorname{sim}($ ) não

15. Como enviá-las?

\section{Referências}

1. ANVISA. Agência Nacional de Vigilância Sanitária. Gerenciamento dos resíduos de serviços de saúde. Tecnologia em serviços de saúde, séries temáticas ANVISA, v. 1, 2006/2007.

2. BECKER, D. Diagnóstico laboratorial: avaliação de métodos de diagnósticos das principais doenças infecciosas, parasitárias e auto-imunes. Correlação clínico-laboratorial.

2. ed. São Paulo: Guanabara Koogan, c2001. 443 p.

3. BERBATA, V. S.; HEARD, K.; DART, R. C. Inhalation abuse of methanol products: elevated methanol and formate levels without vision loss. American Journal of Emergency Medicine, v. 24, p. 725-8, 2006. 
4. BERLITZ, F. A. Controle da qualidade no laboratório clínico: alinhando melhoria de processos, confiabilidade e segurança do paciente. Rio de Janeiro, Jornal Brasileiro de Patologia e Medicina Laboratorial, v. 46, n. 5, 2010.

5. GARCIA, L. P.; ZANETTI-RAMOS, B. G. Gerenciamento dos resíduos de serviços de saúde: uma questão de biossegurança. Rio de Janeiro, Caderno de Saúde Pública, v. 20, n. 3, p. 744-52, 2004.

6. GONÇALVES, A. C. Tratamento de efluentes contendo cianeto livre através do sistema H202/UV. 2004. Tese (Doutorado em Ciência dos Materiais e Metalurgia), Departamento de Ciência dos Materiais e Metalurgia, Pontifícia Universidade Católica do Rio de Janeiro, Rio de Janeiro, 2004.

7. GROTTO, H. Z. W. O hemograma: importância para a interpretação da biópsia. São Paulo, Revista Brasileira de Hematologia e Hemoterapia, v. 31, n. 3, 2009.

8. HOFFMANN, L. P. et al. Avaliação dos índices hematimétricos emitidos pelos contadores hematológicos Pentra 120
Range e Sysmex XT-2000i. Revista Brasileira Análises Clínicas, v. 39, n. 1, p. 25-8, 2007.

9. LIMA, L. M. Q. Lixo: tratamento e biorremediação. 3. ed. rev. e ampl. São Paulo: Hemus, c2004. 265 p. ISBN 8528901491 (broch.).

10. MASTEN, S.; Methylolurea. Review of toxicological literature. Toxicological summary for methylolurea (1000-82-4). 2002.

11. MUGNOL, K. C. U.; FERRAZ, M. B. Sistema de informação como ferramenta de cálculo e gestão de custos em laboratórios de análises clínicas. Rio de Janeiro, Jornal Brasileiro de Patologia e Medicina Laboratorial; v. 42, n. 2, 2006.

12. RAPAPORT, S. I. Hematologia: introdução. 2. ed. São Paulo: Roca, c1990. 450 p.

13. TREICHEL, J. L. et al. Formate, the toxic metabolite of methanol, in cultured ocular cells. Neurotoxicology, v. 24, p. 825-34, 2003.

14. VIEIRA, L. M. F. Os 60 anos da SBPC/ML e a evolução da medicina laboratorial. Rio de Janeiro, Jornal Brasileiro de Patologia e Medicina Laboratorial, v. 40, n. 5, 2004. 